\section{Condition of British science}

SIR-Your first leading article on 22 March (Nature 344, 275; 1990) was entitled "Bringing research back to life". It was subtitled "Having all but killed it off, the British government is now brooding on how best to restore a oncesuccessful research enterprise to good health". These are remarkable statements, which were curiously unsupported in the body of the article by a single figure or statistic. Let us test these statements against some known facts.

Harry Atkinson and Philippa Rogers of the Science and Engineering Research Council have shown that Britain employs 128,000 researchers in all, supported by a further 155,000 technical staff. Does Nature really believe that a total of 283,000 scientific staff represents a science that has been "all but killed off"?

The universities, moreover, have done well over the past ten years. University Grants Committee statistics show that there were 40,246 full time academics in 1976-77, and that this figure had risen to 47,038 by $1986-87$. Most of this expansion was in the sciences.

Britons publish a lot of papers. The Evaluation of National Performance in Basic Research (ABRC Science Policy Studies, No. 1, 1986) showed that, for 1982, we published 432 papers per million population, compared with 483 or 465 for the United States or Canada respectively, and 295, 279 or 174 for Germany, France or Japan respectively.

The quality of our science remains superb. Current Contents of 28 November 1988, 12 December 1988 and 6 February 1989 shows that, of the 300 most cited papers published during 1985-86, only the United States produced more than Britain. Our papers attracted more citations than those of the French, German or Japanese.

Our science is well funded. The International Comparison of Governmental Funding of Academic and Academically Related Research (ABRC Science Policy Studies, No. 2, 1986) shows that, as a percentage of gross domestic product, we may not match the West German or French figures, but we out-perform the Americans or the Japanese. Moreover, our non-governmental support for science is increasing fast. The medical charities' support for research has doubled in ten years, and now matches that of the Medical Research Council. Industrial support for academic science has also doubled in the past ten years, as has been acknowledged by both the Association of University Teachers (submission to the Department of Education and Science, 1989) and the Labour Party (Science for the Citizen, Jeremy Bray, 1989).

Problems remain, of course. Too many alpha-related projects go unfunded, but sadly this is an international problem. In the United States, both the National Institute of Health and the National Science Foundation are turning down two-thirds of their alpha-rated projects. Science would like to grow at a greater rate than the economy, whatever the country, but obviously it cannot.

We lose too many high quality scientists to the United States but, as I proposed in my pamphlet for the Centre for Policy Studies (Science Fiction, 1989), this reflects our universities' employment policies (tenure, fixed salaries, dual funding) rather than our overall funding.

Your leading article admitted that its assessment was "subjective", but if you go around depressing people with unsupported statements, we will all go home in despair and your subjective obiturary will become self-fulfilling.

TERENCE KEALEY

Department of Clinical Biochemistry, Addenbrooke's Hospital,

Hills Road, Cambridge CB2 2QR, UK

SIR-Your News columns suggest that everyone is so short of scientists that they are trying to poach them from everyone else. The need may be a real one, but my difficulty is the belief that, were cash available, there would be no problem in increasing the supply.

Surely this belief is wholly unscientific? If the concept of evolutionary adaptation is true, then humans are still adapted to live in conditions of subsistence agriculture. (After all, most of them still do so.) Genetic variance, which produces individuals whose ability to manipulate abstract ideas varies between that of the village idiot and the professor of comparative ambiguity, will always produce a small but constant fraction of the population who are potential scientists. There has been insufficient time over the past few centuries for selection to increase this proportion, although such a change might well happen eventually.

That there now seems to be more of them than before is partly due to the increase in world population and partly to the effect of contiguity. In very small communities, the potential scientific heads will rarely if ever meet those of their own kind, so that inability to 'knock spots off each other' will retard the appearance and growth of scientific ideas. As communities increase in population, and tend to overlap, such contact becomes more and more possible, and scientific habits of thought slowly develop, even if not among the mass of humans. It is no surprise that historians of science insist that the dissemination of ideas is a major cause of the rapid growth of science in the past two centuries.

When one realizes that personal aptitude as well as genetic influences are necessary to produce good scientific heads, it is hard not to think that the present lack of scientists is due to the fact that we have been scraping the barrel for a long time, and that, however we try, there are few more to come by.

89 Apton Road,

Bishop's Stortford, Herts CM23 3ST, UK

\section{Romanian minority}

SIR-Television viewers in many countries will have witnessed a crowd brutally assault members of the Hungarian minority in the Romanian city of Tirgu Mures (Marosvásárhely) on 20 March.

One of the victims was Dr Mihály Péter, professor of microbiology at the School of Medicine and Pharmacology. Péter (61) was taking part in a peaceful demonstration asking that Hungarian be reestablished as a language of education at the university. The use of Hungarian was banned under the Ceausescu regime.

Péter is a popular educator who gained international reputation for developing a hepatitis-B vaccine in the early seventies.

We ask our scientific colleagues to express their concern for Dr Péter.

TIBOR DEAKK

Department of Microbiology,

University of Horticulture,

Budapest, Hungary

Agricultural Biotechnology Center,

Gödöllo, Hungary

\section{Which came first?}

SIR-S. Chandrasekhar (Nature 344, 285; 1990 ) says that the human mind created mathematics, through "speculative thought". He is amazed that this artificial creation turns out to be an excellent predictor of the physical world.

I suggest that he has got it the wrong way round. The physical world created the human brain, through evolution. If the world is mathematical, that fact must show in brain function.

Long before humans walked the Earth, there was a payoff in modelling the world as moving objects in an environment. Projectiles fly in conic curves, predators circle, a straight line is the shortest journey. The brain must surely be wired for mathematics.

A day came when the Greeks took mathematics out of their heads and set it on paper. On that day, predicting the world became a team effort. With the results we see today in physics. Impressive but not surprising.

22 Cromwell Road,

RICHARD BAKER

Kingston KT2 6RE, UK 